\title{
Looking good and judging gazes: The relationship between body ideals, body satisfaction and body practices among Norwegian men and women
}

\author{
Mari Rysst ${ }^{*}$ Ingun Grimstad Klepp \\ National Institute for Consumer Research, Oslo, Norway; ${ }^{*}$ Corresponding Author: mari.rysst@sifo.no
}

Received 25 January 2012; revised 17 February 2012; accepted 6 March 2012

\begin{abstract}
This article compares how people with normal bodies and bodies that deviate from dominant media-depicted body ideals, live with and accept their bodies. Media images of ideal bodies encompass judging gazes. These gazes affect and discipline people and may make it challenging for them to accept their bodies. The data material is part of the interdisciplinary Nordic project called "Beauty comes from within: looking good as a challenge in health promotion". Based on 20 interviews with Norwegian men and women, of whom 10 have particular appearance-related problems, the article discusses the relationship between the media-depicted body ideals, descriptions by informants of what a good-looking body is, body satisfaction and body practices. The article shows resonance between how people describe good-looking bodies and satisfaction or not with own bodies. Women express more dissatisfaction with their bodies than men, but the article shows that many have strategies for trying to accept their bodies as they are. The comparative perspective highlight that the people having deviant bodies, more than those with normal bodies, balance the idea of "being myself" with the idea of "doing the best out of my (bodily) situation". Most interestingly, they show that it is harder to accept handicaps that are changeable, like overweight, than harelips, deformed legs and skin injuries. As such, overweight becomes a double burden.
\end{abstract}

Keywords: Body Ideals; Deviant Bodies; Affect; Governing the Soul; Body Discipline; Judging Gazes

\section{INTRODUCTION}

In Norway, as is much the case in other countries in the West, there exists an increased public interest in health, fitness and looking good. The role of appearance as a motivator for [1] physical activity and healthy diet is believed to be under-communicated. According to the sociologists Shari L. Dworkin and Faye L. Wachs, "few have analyzed how public health and fitness discourse often conflate meeting gendered bodily ideals with a state of health" [2]. The Nordic research project "Beauty comes from within: looking good as a challenge in health promotion" addresses these issues (www.sifo.no/page/ Forskning//10060/73102.html). The aim of that project is to develop knowledge of how discourses on health, consumption and well-being use, interpret and attach importance to appearance. In this article we suggest that the ubiquitous exposure of ideal body images as well as a strong focus on fitness and training, consciously or unconsciously affects the way in which people judge their own and other people's bodies, a judgment that may motivate people into different body practices, such as cosmetic surgery, dieting, and training. Of particular interest is how people with deviant bodies, compared to those with "normal" bodies, cope and live with their bodies in relation to dominant body ideals for looking good. By "deviant" bodies we mean bodies that are visibly overweight (Rune, Gunnar, Rita, Kari, Trine, Cille), or have other characteristics that preclude their conformity with dominant beauty ideals. For this study, this entails a harelip, a deformed leg, a prosthetic leg, skin problems and fire injuries (respectively Rune, Ellen, Frida, Inger and Storm). The other informants do not have these characteristics (Peder, Anders, Tor, Arne, Kalle, Per-Ole, Sigrid, Synne, Tone, Kjerstin) and are termed "normal".

We follow Mike Featherstone in that people "do not necessarily believe or follow the self-improvement 'if you look good you feel good' logic” [3]. However, our material shows that people are affected by such a logic, thus this article aims to explore how and in what ways. We suggest people have internalized the aforementioned logic in different degrees, which motivates them into various body practices. One assumption could be that people with deviant bodies experience more body dissat- 
isfaction than people with normal bodies, leading them to use more money and effort in trying to come closer to the ideals. In other words, the present situation of body focus is extra tough for those with deviant bodies. Alternatively, people with deviant bodies know they can never match the body ideals, and therefore relax more regarding appearance in general and think less about how they look than do people with normal bodies. More precisely we propose answers to the following questions:

- How do informants' descriptions of idealized bodies resonate with their satisfaction with and acceptance of their own bodies?

- In what ways and to which extent do they engage in body practices that may be inspired by dominant body ideals, and how do these vary between people with normal and deviant bodies?

- What are the differences and similarities of body practices between people with normal and deviant bodies, and how are these to be understood?

The data consists of 20 interviews, 11 women and 9 men, ranging in age from 18 to 62 years. In addition, four widely read Norwegian magazines and a leading newspaper (Aftenposten) are included. The informants have been selected and categorized according to sex, age, frequency and type of physical activity, body size and body deviances. These variables were chosen on the assumption that they are relevant for how people concepttualize and relate both to body ideals and their own bodies. The informants are presented in Figures $\mathbf{1}$ and $\mathbf{2}$.

By "training" we understand activities that occur at least once a week and that make one perspire. The informants' actual ages are put in brackets after their pseudonyms.

\begin{tabular}{|c|c|c|c|c|c|}
\hline \multicolumn{2}{|c|}{} & \multicolumn{2}{|c|}{ Below 40 } & \multicolumn{2}{c|}{ Age } \\
\hline \multirow{4}{*}{$\begin{array}{c}\text { Physical } \\
\text { activity }\end{array}$} & & \multicolumn{2}{|c|}{ Body deviance } & \multicolumn{2}{c|}{ Above 40 } \\
\cline { 2 - 6 } & Yes & No & Yes deviance & No \\
\cline { 2 - 6 } & Train & & $\begin{array}{c}\text { Synne } \\
\text { Kjerstin }\end{array}$ & & $\begin{array}{c}\text { Tone } \\
\text { Sigrid }\end{array}$ \\
\hline \multirow{4}{*}{$\begin{array}{c}\text { Don't } \\
\text { train }\end{array}$} & $\begin{array}{c}\text { Frida Cille } \\
\text { Rita Ellen }\end{array}$ & & $\begin{array}{c}\text { Trine Kari } \\
\text { Inger }\end{array}$ & \\
\hline
\end{tabular}

Figure 1. Women informants (11).

\begin{tabular}{|l|l|c|c|c|c|}
\hline \multirow{4}{*}{$\begin{array}{l}\text { Physical } \\
\text { activity }\end{array}$} & \multicolumn{2}{|c|}{} & \multicolumn{2}{c|}{ Age } \\
\cline { 2 - 6 } & & \multicolumn{2}{|c|}{ Below 40 } & \multicolumn{2}{c|}{ Above 40 } \\
\cline { 2 - 5 } & & \multicolumn{2}{|c|}{ Body deviance } & \multicolumn{2}{c|}{ Body deviance } \\
\cline { 2 - 5 } & \multicolumn{2}{|c|}{ Yes } & No & Yes & No \\
\cline { 2 - 6 } & Train & Storm & $\begin{array}{c}\text { Peder } \\
\text { Anders }\end{array}$ & & $\begin{array}{c}\text { Tor } \\
\text { Arne }\end{array}$ \\
\hline \multirow{4}{*}{} & $\begin{array}{l}\text { Don't } \\
\text { trazin }\end{array}$ & & $\begin{array}{c}\text { Per-Ole } \\
\text { Kalle }\end{array}$ & $\begin{array}{c}\text { Rune } \\
\text { Gunnar }\end{array}$ & \\
\hline
\end{tabular}

Figure 2. Men informants (9).

\section{BODY IMAGE AND JUDGING GAZES}

The focus on good-looking male and female bodies fills the coloured press, fashion and fitness magazines, newspapers as well as many TV programs and advertisements all over the world. The relationship between looking good according to physical ideals depicted in the media and consumer culture is here amply highlighted. We have screened three widely read Norwegian magazines, (the fashion magazine $K K$, the celebrity magazine Se \& Hør (Look \& Hear) and HENNE (Her), and suggest they represent dominant conceptualizations of ideal bodies, or "the dream body." The September 2009 issue of HENNE has the headline, "This is how you get the dream body," and includes a little booklet on relevant exercises. Looking good from working out seems to be a dominant idealin the magazines we screened [4]. The emphasis is on improved appearance, not health. Articles in Se \&Hør illustrate how celebrity bodies are scrutinized for deviations from the very narrowly defined body ideal of "just enough" fat and muscles, and not "too much" or "too little" as defined by the media articles [4]. This scrutiny of celebrity bodies is obviously not just a Norwegian phenomenon [3].

The recommended procedures for looking better include commercialized body practices or "appearance management" [5] which refer to body practices such as dieting, exercising, the use of make-up and cosmetic surgery. Meredith Jones suggests that the present situation is that of a "makeover culture" which merges consumer and medical "cultures," of which cosmetic surgery is a good example [6,7]. We assume that this ubiquitous exposure to body ideals affects the way in which people judge their own and other people's bodies. This has implications for their satisfaction with their own bodiesas well as body practices related to appearance and looking good.

Michel Foucault argues that the body is the target of subtle disciplinary practices that seek to regulate its existence [8]. He contends that with the dispersion of power in the transition from pre-modern to contemporary society, power is not owned by one group used to dominate another; power is more dispersed and involves a willingness to internalize the gaze of a generalized other who may be watching [8]. This gaze need not be connected to particular men and women, but experienced as the possibility that others may be watching. These judging gazes are subjectively experienced as they discipline the body according to expectations implied in this gaze, which have implications for body practices.

In the present article, body images in selected magazines are treated as representations of a "dispersion of power" and the gaze of a generalized other that may be watching [8]. The article focuses on attitudes and judging 
gazes found among Norwegian men and women, but with special attention paid to those with deviant appearances. The article suggests ways of understanding the substance and content of these gazes and their implications for how people live with their bodies in relation to the concepts of "healthism” [2], "governing the soul” [9] and cognitive schemas/models [10].

The concept of healthism comes from public health and medical sociology, and concerns a political ideology that has its roots in the US in the 1970's and which shifted health responsibility from the state to the individual [11]. The sociologist Nikolas Rose, in line withFoucault, has since developed the concept further, describing it as "a doctrine that links the public objectives for the good health and good order of the social body with the desire of individuals for health and well-being” [12]. Rose's argument is informed by Foucault's idea of "governmentality," which implies that different disciplenary practices in schools, the army, hospitals, prisons and manufacturing industries, produce “docile bodies," inclined to obey the regimes of power in society [13]. Rose argues that since people want to be healthy, the state has an easy job in stimulating a healthy lifestyle. This is because advertising and capitalist persuasions otherwise tend to lead people to internalize the message of healthism without state intervention [11].

Foucault and Rose's way of thinking has also inspired the feminist and media researcher Angela McRobbie. She argues that patriarchal authority today, what she terms "the Symbolic," in the age of post-feminism, is exerted through the commercial arena's inextricable links with the fashion-beauty complex. According to McRobbie, magazines and the commercial domain encompass disciplining gazes, the content of which is constructed and defined by some dominant "Symbolic." Women and girls, but also men and boys, come to experience their bodies as if someone were looking at them, leading to disciplining body practices, or what Rose argues is an aspect of "governing the soul" [9].

A supplementary way of looking at the relationship between body ideals and body practices is through the concepts of cognitive schemas/cultural models as having motivating forces [10]. This way of thinking is closely related to the view of judging gazes having affective intensities [3], and bodies without an image [3], because action is understood to result from unconscious, inner bodily intensities, a sort of "gut feeling." Body ideals, as they are shown "everywhere," are cultural models of ideal bodies which people are motivated by in various ways, and internalize in different degrees, as we will show below.

If much research is correct, depictions of idealized body images thus affect how different people think about body ideals and their own bodies [5,6,14,15]. Alterna- tively, ideal body images may make people experience affective intensities [3] that motivate them into beautification practices. The philosopher and feminist Susan Bordo seems to be sure of the media's influence, writing about what she calls "the empire of images" and how they influence people without them knowing and thinking much about it. In other words "the empire of images" is internalized, becoming parts of "gut feelings", and motivating people into action without them necessarily being consciously aware of these connections. This "empire of images" has changed the perception of many to the extent that they look at big bodies as ugly and slim figures as beautiful [15]. As such, Bordo seems to be in accordance with the argument of Rose and also that of McRobbie regarding how the commercial domain "becomes the source of authority and judgement for young women" [16]. In a new book on discrimination of appearance, professor of law Deborah Rhode writes that, "The media in general and advertisers in particular have played an important role in magnifying the importance of appearance and the pressures to enhance it" [17]. According to Dworkin and Wachs, this increasingly also relates to men, in that their "experiences of self and identity are coming to exhibit many of the characteristics of women's experience of being objectified" [2]. The sociologist Michael Atkinson shows the increased interest of Canadian men in cosmetic bodywork and how they remake those body practices into acceptable masculinities, also called “male femininities" [18].

This article emerges from qualitative interviews in the aforementioned "Beauty" project. Different ways of doing "man" and "woman" are understood to be constructed and derived from body ideals that imply male and female gazes informed by a makeover culture, discourses of thinness, fitness, the "war on obesity" [19] and body dissatisfaction [15,14,19,20]. "Body ideals” are understood to be based on how good-looking bodies are described in media and magazines [4] combined with the characteristics men and women in this study underline in their description of a "good-looking" and "sexy" body. The overarching aim of this article is to show, through comparison of people with normal and deviant bodies, how Foucault, Rose and McRobbie's way of thinking sheds light on how Norwegian men and women engage in body practices related to appearance and looking good. The characteristics that constitute the dominant ideals have implications for body satisfaction and body practices. Trying to match ideals involves different kinds of purchases. The following pages may be read as an empirical exploration of power and discipline regarding body practices among people in Norway. To our knowledge, there exist no other studies that explicitly focus on the relationship between body ideals and body practices in a comparative perspective. 


\section{DESCRIPTIONS OF GOOD-LOOKING BODIES}

Most of the young men interviewed (below 40), irespective of body appearance, have clear opinion of how they visualize a good-looking and sexy body. Three of the young men use the term "hourglass" figure as an ideal for women, a term also found in Norwegian magazines. One young man, Peder (18), represents these views by saying that good-looking male bodies have "narrow hips and broad shoulders and a broad back. Fat bodies, or plump bodies, are not that good-looking. In addition sexy bodies are muscular, so defined muscles are visible.”

For men over 40 years and categorized as having deviant bodies, their descriptions vary from those of the younger men. Rune (who has a hare-lip and is overweight) says he has not reflected much on other men's bodies, and where women are concerned; it is charm and personality that counts. So says Gunnar, who is overweight, and emphasises the importance of the attractiveness of "normal" bodies. Except for his big stomach, he views his own body as “normal." He says he doesn't have "a definite opinion about what is nice and ugly. I think not too thin or too fat, that the body has a normal shape, I like that on both men and women. I think normal bodies are sexy. I really think so, for both women and men. And I don't have any opinion apart from that." When the descriptions from men over 40 with normal bodies are compared to the descriptions of those over 40 with deviant ones, the former are more clear that goodlooking bodies are to be slim and moderately fit.

How good-looking bodies on men and women are described does not seem to vary between men and women. For instance, some of the women also used the term "hourglass" figure as an ideal for women, and referred to the discourses of thin-fat and fit-unfit in their descriptions. The most clear, determined, and precise descriptions came largely from women under 40 years of age and then from those who trained regularly. This group is represented here by Synne (18), who says that "a goodlooking body for women is Not too thin, but maybe relatively straight and thin legs maybe boobs that match the body, not too big. And a flat stomach. I think tall boys are nice. And sporty rather than big muscles only. That you look trained and... perhaps a bit suntanned and a good body posture. That concerns girls as well. And perhaps some curves, 'hourglass' Looking healthy”.

There is a tendency in the material for men and women with bodies that deviate from the ideals, to provide unclear and poorer descriptions and point to "personality" and "charm" as important for "looking good," as indicated by Rune and Gunnar above. They tend to emphasise "inner” more than "outer” qualities. Storm (30) who was injured in a fire is an exception, however. He has clear opinions on good-looking bodies for both sexes, opinions that are in line with those of Peder, the 18 year old whose ideal male body was mentioned above. The overweight informants seem to downplay appearance more than those with other deviances. Kari, who has a larger body, mentioned that she found "men who cared for others to be sexy" and did not describe good-looking and sexy bodies in much detail. Most of the women relate to the discourse of thinness: "I absolutely do not like very skinny girls" (Frida, 25), and "a sexy body has to do with, yes, being thin or fat” (Kjerstin, 30). The comments of the overweight women Trine (62) and Kari (42) suggest that those who deviate from the norms of the ideal body have a tendency to describe their ideal of a goodlooking body more in terms of how they say they look themselves. Trine says that "a good-looking female body is that it is well proportioned, a bit sexy perhaps... A sexy body is having nice boobs and a not too big butt (laughs.) And the sexy ones, they are well proportioned. Long legs... well proportioned. And I suppose you have a handsome face as well, perhaps. A good-looking body on a man is also well proportioned, preferably a bit trained, but need not have a six-pack or the like, and has a small butt as well. An unsexy body, for women, is to be neither too thin nor too fat. And maybe untrained... no, not untrained".

Trine further insists that a good-looking body doesn't have to be trained, but by saying that she implicitly indicates that trained bodies are an ideal. And Kari says: "For a good-looking body may just as well be chubby as thin, really. To me it doesn't matter.” By saying this, Trine and Kari may be understood to legitimise and normalize their own oversized and untrained bodies and thus perhaps to feel better about them, just as Rune and Gunnar may do when they describe their own ideals and bodies. Cille (36), who is the most obese in the study, is the most explicit on this issue: "I have always had a thing against highly trained people. I suppose it is a way of legitimising myself. But besides that, I think a sexy body has a lot to do with the personality that shines through.” Personality is thus understood to shine through the body, as something distinct, as inner qualities that make one sparkle. Rita has a similar attitude: "I focused more on the man's outside before, now it's more about what's inside.” In sum, when comparing people with normal and deviant bodies, it seems that the latter have a clearer tendency to describe ideal bodies in line with how they describe their own.

In relation to the issue of healthism mentioned earlier, the way health is referred to in descriptions of "looking good" among the informants is of interest. Concerning whether the concept of "health" is involved or not in the descriptions of a good-looking body, only 2 of the 9 men used it, compared to 7 of 11 women. The two men were 
both below 40 years of age (Anders and Per-Ole, both 30.)Anders states that "To look healthy is the common denominator for both sexes," which we read to imply that moderate but not excessive muscles are acceptable. Per-Ole describes "A healthy body, not too thin, but not visibly overweight either." These two men point to a relationship between healthy and good-looking bodies, and the fact that these bodies have to balance between extremes for both sexes. This is the overall impression from the men's descriptions. Being obese is the least attractive, illustrating how the "war on obesity" [19] is also present among Norwegians. While the discourse of fitness is referred to in all of the young men's descriptions, only two among the elderly men explicitly refer to fit bodies. This vague distinction between the younger and older men can be understood as a generational discrepancy. The issue of training and fitness studios seems to be more present in the lives of young people. The elderly men may be more acquainted with the terms "exercising” (mosjonere) and "going for a walk” (gåpåtur), than "training", which they associate more with training for competitive sports.

That more women than men in this material relate to the discourse of health may be a coincidence, or it may indicate that women are more informed of the relationship between beauty, health, and exercise than men. It may also suggest that women hesitate more than men when making self-beautification the explicit reasons for their exercise. Nevertheless, the fact that the men and women actually use "health" in their descriptions suggests the existence of the health discourse in relation to looking good. Here we see an indication of a relationship between being healthy and being good-looking and how that relationship is an effective governing technology [9]. Moderate muscles symbolize health and are at the same time esteemed to be "beautiful,” Being healthy and being beautiful are likely both attractive goals, suggesting the relevance of the argument of sociologist Sarah Moore: “doing health" may have become a means of “doing gender" [21].

It is also worth noting that 9 out of 11 women describe the good-looking body by using the word "trained", which again highlights the fact that trained bodies are known body ideals for both men and women regardless of deviation or not. As such, the majority of informants' descriptions resonate well with how the aforementioned magazines describe idealized bodies, as well as with foreign literature. According to Rudd \& Lennon, "Facial attractiveness, thinness, and fitness form the basis of the contemporary American standard of ideal female beauty" [5], an argument confirmed by others as well [22-25]. In other words, thinness and fitness may be read to dominate body ideals, and thus the judging gazes. The images work as powerful disciplinary technologies as "the cult of thinness" [25] or "tyranny of slenderness" [15] are reported to increase the stigma of being obese and to create body dissatisfaction in younger and younger age groups [14]. How are body dissatisfaction and body acceptance reflected in the Norwegian material, and are there any differences in this regard between those with normal and those with deviant bodies?

\section{BODY DISSATISFACTION AND BODY ACCEPTANCE}

Dworkin and Wachs argue that the idealized body ideals in magazines seldom fit any natural body, in fact even professional athletes rarely measure up [3,2]. Labre and Walsh-Childers [26] show that fashion magazines reinforce unrealistic images of beauty. Girls as young as five and six report reading such magazines and identify with well-known models and celebrities [17,27,28,]. A study by Smeesters et al. examined the psychological mechanisms involved in women's self-esteem when they were exposed tomedia images of thin and heavy models. They found that it is not the absolute size of the model, but the relative distance between the model and the consumer's body size that determines the ad's influence on self-esteem [29].

Being exposed to impossible body ideals may inflict on people's self-esteem and create a continuous drive in some to improve parts of their bodies, given that there are likely always body parts that could look better. Argentina and Brazil are cases in point, because cosmetic surgery is almost part of a normal feminine masquerade in these countries [6]. However, according to the biggest Norwegian newspaper Aftenposten, an increasing amount of Norwegian women and men have, in recent years, had cosmetic surgery such as breast augmentation, liposuction and eye lifts. Norwegian men are said to want to look younger in order to have a better professional life; they don't want to be looked upon as “old," which reduces their chance of getting a (new) job (Aftenposten 20/9-2009).A similar argument is made by Atkinson about Canadians [18].

A possible increased struggle for body perfection is also reflected in our material, among men and women, young and old, having normal or deviant bodies. It seems that people with normal bodies are just as preoccupied with perfection as those with deviances. Frida (25), who has a leg normal prosthesis, says: "Everybody would like to change something about their bodies and that includes me as well.” Tone (45) who has a normal body, but has reduced her breasts and had liposuction after childbirth, says: "I suppose I am like many other girls in that I would like to lose four to five kilos." Cosmetic surgery is justified for the purpose of raising low self-esteem, and thus of giving women a better life [6]. This is the ulti- 
mate illustration of subjected power and of how medical expertise subtly creates new technologies that govern people's souls in an illusion of free choice $[8,9]$.

Similar attitudes concerning female dissatisfaction with the body were illustrated in an issue of the Norwegian variant of Elle in Summer 2009. Five Norwegian celebrities were photographed almost nude and questioned on their attitudes towards their bodies. All were dissatisfied. The newspaper Aftenposten (2/7-2009) refers to a Norwegian study made in 2005, whichshows that $54 \%$ of the women were dissatisfied with their bodies, compared to $35 \%$ of the men.

Body dissatisfaction is thus not only a female "problem.” Boys and men are also disciplined by media images and consumer culture: "A common problem is however, that I am never really satisfied, so there will always be some detail to improve that's just how it is" (Peder, 18). Storm (30) says that "I am relatively welltrained, but could be a bitslimmer." Among our twenty informants, only women are read to be "not satisfied" [15]. So in sum, whatever the reasons the informants in this material give for being dissatisfied, they support the claim made by some of the informants about there being more female dissatisfaction than male. Most interestingly, people with normal bodies seem almost more dissatisfied than those with "deviant" ones. Peder exemplifies this when he says "there is always something that could look better." As we will discuss below, the "deviant" people have accepted not having ideal bodies, stating "that is just how I am."

Most of the informants with deviant bodies emphasise that they have accepted themselves as they are, although they describe their body deficiency as a "complex." It seems that they challenge and try to overcome this complex in different ways by saying that they have accepted their body "handicap". To accept oneself appears not only to be a personal endeavour, but just as much as a norm according to which they strive to live. Therefore the means for achieving this goal become a clearly structured narrative with clear turns. For instance, Storm recounts how one strategy for accepting his appearance was to change his own approach to his situation. He experienced a dramatic fire accident when he was a child. It took many years and many operations were endured before treatment ended. In his first year in high school he had his own shower and bathroom (although this was not a live-in high school). "I am sure I could have been offered my own shower and bathroom the rest of my life," but he turned the offer down and started to reason that, "Ok, I am not like you, that's how it is. And people will stare for a while... but they get used to it. And everybody has some kind of...more or less...deficiency or other that they hesitate showing."

Storm highlights the aforementioned argument about people in general never achieving satisfaction with their bodies. Later in the interview Storm explains his ambiguous relationship to his injury. His skin is very dry and has to be moistened regularly. But he doesn't let it be a hindrance: "If I am some place where it is hot, I take off my shirt and show my bare chest. It might just as well be me who is the first to do so. And then I could have said that it would have been cool if I had a better body. But I have... if I trained more, I could have had it. But the scars are so incorporated that those are not the first things about my body that I think should not be there.”

Storm's acceptance strategy resembles that of other informants with deviant bodies, and resonates with the point made about describing body ideals in line with how they perceive their own bodies. The challenges connected to a divergent appearance are challenges the informants say they would not have missed. This may be understood as an internalization of the idea of "positive thinking" which results in turning challenges into potential personal growth [30].

The emphasis on a positive but realistic way of thinkingsheds light on how Storm and others refer tolooks when they explain choices and habits in other issues related to appearance. For instance, appearance is a theme in why Storm has chosen a very short haircut. He says he actually likes long hair better, but because he has:

"...started to lose some hair, having long hair became sort of 'comb over-like'. And that is definitely not me. I believe that has very much to do with the fire injury as well. It is kind of no use in trying to hide things as they are, because that's how they are. You can choose (to accept me as I am or not)."

In the same manner, he explains his lack of teenage revolt by referring to his fire injury: "I guess I adapted to society in order not to be noticed by anyone, because I was noticed by everyone already. He has never considered buying shoes that make him look taller. "I have been very forced to decide for myself who I am, how I look, and that's how it is. And then I have accepted that this is how it is." Storm doesn't use clothes to hide his scars. This may be understood as a strategy to ignore his scars and view himself as "normal." He sums up the interview by saying: "One has to accept what it is impossible to do anything about, otherwise things get too difficult." He is probably right, but it also implies that what it is possible to do something about, but one fails to achieve, can be harder to live with.

Even though Storm says he has accepted himself and his body, he is engaged in making the best out of his appearance, similar to Peder. Training and diet are included in his strategy to appear well-built and strong, even though he is short. Nonetheless, he is not willing to do all that is possible; he refuses both hormone products and cosmetic surgery. 
Similar to Storm, other informants with deficiencies also use the rhetoric "everybody has some kind of deficiency" to tone down their own problems. Ellen (29), with a deformed leg says: "Some people are born with a crooked nose, and I am born with crooked legs.” Still, she has to remind herself continuously that things could have been worse: "I can say that I am not satisfied with my leg. But then I also often think that it could have been worse. I am not that bad after all, it is possible to live with it. It's not that I have thought differently, but it is the leg that I am the least dissatisfied with, actually.”

Like Ellen, many of the others have used a lot of energy to accept and to be reconciled with their appearances. The informants were asked if there was something they didn't like so much about their appearances, but these did not always stress their "handicaps". The handicaps are both irreversible, and have been accepted to some extent. Storm does not mention his fire injuries first, but instead his height: "I could have been a bit taller. I am $168 \mathrm{~cm}$, that is the average height for women in Norway." He adds that he would not opt to be without the fire scars on his skin: "It has been part of my life for so long, so to wish it gone is almost similar to wishing away parts of my personality." Frida expresses much the same regarding her amputated leg: "so I know that if I didn't have what I have, I wouldn't have become the person I am today." Later in the interview, most interestingly, she talks about her breast implants and does not downplay the possibility that the surgery was a compensatory procedure "for my foot" (Frida). She explains that "I try not to make the foot a complex, because we should be content with how we are, but still, I lack some thing or other, I lack that foot. However, absolutely, the breasts compensate."

Another approach to accepting oneself, besides the one Storm, Ellen and Frida have chosen, is to tone down the importance of appearance and ignore the body as an important part of self. This is particularly evident among the overweight informants. As mentioned, Gunnar, Rune and Kari underline the inner self. Cille (36) is the most extreme. Shehad obesity surgery a few weeks before the interview. Before her operation, she had lived a life in which she had distanced herself from actually having a body at all: she never looked at herself in a mirror, she never used a scale, and she seldom bought clothes. Her self-esteem concerning her appearance was extremely low. Cille preferred to avoid objectifying her body; she tried to repress having a body. Her health problems and aesthetic ideals may be said to have motivated her into getting the operation. From an experience of not objectifying her body by repressing the fact that she even had a body — which had made her put on kilos without noticing it-to objectifyingher bodyin terms of the size it had become, surgery became the last resort. To ignore the body was a strategy that worked regarding self-esteem, but it eventually resulted in such a huge physical problem that something had to be done about it. In a sense, it could be said that her body was without image [3]

\section{BODY IDEALS AND BODY PRACTICES}

In this last section, we will compare how the informants with "normal" and "divergent" bodies engage in different body practices related to dominant ideals and their own bodies. Of importance here is how they express satisfaction with their own bodies and are motivated into different body practices. Peder (18) and Storm (30) clearly say that they work on improving muscles they are dissatisfied with, and both want to lose some fat, particularly on their stomachs. Their description of good-looking bodies can be understood as aims and motivations for their training, and clearly resonate with the body ideals presented in magazines. That is particularly so concerning Peder, who explicitly talks about the importance of correct diet for building muscles. He is working to improve his own body and says "It has become much more muscular since I started training, but it is not yet where I want it to be. I want to build some more muscles and get rid of the fat on my stomach so that I can show what is called a 'six-pack'.” Peder's description of his body practices may be read to illustrate how strongly he is disciplined and affected by a judging gaze. This gaze, which also applies to Storm and his fire injuries, perfectly reflects the magazine images presented earlier. They objectifythemselves in light of the dominant gaze and act according to it. They try to make their bodies look good in light of body ideals, which resonate with the ones in the magazines. These ideals may thus be read as technologies of governing their souls [9], affecting those with normal and deviant bodies in the same manner. They have all internalized the body ideal of slim and trained bodies, and are motivated by this ideal in their body practices. This also concerns the slim and relatively fit women. Synne (18) says: "On my own body I like my arms. But not my hips and butt and thighs. I go to a fitness studio regularly and work on both arms, my stomach and things like that." She works with those body parts that she finds do not conform to the body ideals as a consequence of her objectification of her own body. It can be noted that the images have affected her body so as to motivate her into these practices [3].

Ellen and Frida, who both have leg deficiencies, don't train regularly, but say they plan to do so. Instead they walk and do exercises at home. The point here is that they know they should train and work on body parts they are not satisfied with, which for both are their stomachs. Their legs have become parts of their personality and a 
defect they have accepted. It is possible that their legs have hindered them in attending fitness studios, because of the attention they would get. As such, their internalization of body ideals has not motivated them into the same extensive training as Synne and others with normal bodies.

To a similar extent this also concerns the overweight Gunnar, who says that "I know my stomach is too big. But besides that, I think my body is quite normal. I walk or take the bicycle to work every day in order to get some regular exercise." Being "normal" for Gunnar means fitting in with the crowd; to be sort of average. His subjective gaze judges himself as "normal" despite his big stomach, while other people's objectifying gaze would evaluate him as "overweight." The judging media gaze is less reflected here. Similarly, Rune is moderately concerned about his own oversized stomach, yet shows little interest in doing something about it. This uncertainty and perhaps unwillingness to depict body ideals shown by both Gunnar and Rune indicate that the way these men think about and "describe" the good-looking body resonates more with how they view their own bodies and body practices than with any media-derived body ideals. They both say that more exercise would do no harm, but have no serious intentions of increasing their exercise. It is possible to interpret these two men as not having internalized the media's judging gaze to the same extent as the trainers. Or put differently, that their souls are not easily governed by dominant body ideals. This notion concerns Trine as well, who says: "What I like about my own body is that I have long, relatively nice legs, at least that is what I often hear from the girls at work. I could have lost ten to twelve kilos without that doing any harm. Today I am repeatedly on diet, but I need more exercise. And that I am too lazy to do."

The descriptions from the unfit and "big" people may at first be understood to mean that they have not internalized the media's judging gaze as strongly as the others. A second interpretationis resignation. They have tried many times to diet and lose weight, but the kilos have returned. Dieting is done both for aesthetic and health reasons, but the fact that they try dieting illustrates that slim body ideals discipline their bodies even though slimness is not explicitly mentioned in their descriptions of beautiful bodies. Therefore it is our contention that they may have internalized the dominant ideals as strongly as the others, but repress or attempt to ignore them in their everyday life. With the exception of Cille, they want to give the impression that they have a relaxed attitude towards their big body shapes, and thus emphasize "inner" qualities. We suggest, however, that being overweight may be both cause and effect: because they are bigger than many others, they don't care how they look in general. They have not internalized the judging gaze to any extent, which may lead to more weight gain over the years. In other words, the cause and effect of obesity are manifold and complicated. These cases may be read to indicate limits of the ideal body discourse: some people, for different reasons, are just not interested in how bodies look.

\section{CONCLUSION}

In this article we conclude that post-feminist masquerades and healthism meet in this era of neo-liberalism and are reflected in what the women and men in the Beauty project say about ideal bodies and their current body projects. Both women and men, with normal and deviant bodies, are subjected to self-surveillance according to some conscious or unconscious judging gazes and the technologies regarding looking good which affect their body satisfaction and self-esteem [2,3,18]. People with deviant bodies do not seem more dissatisfied with their bodies than others. Not all the informants train or exercise in order to be healthy orto match up to the body ideals, but they all know they should. It is evident from the interviews that it is not only women who are objectified by consumer culture. At the same time they are also "subjectified" because they (say they) act on their experienced objectification. In these matters the spheres of women and men converge, or at the very least overlap. They all react to, perceive, and are affected by body images in varying ways resulting in different ways of doing gender.

We suggest the poignancy and relevancy in understanding what is happening in light of Foucault's, Rose's and McRobbie's argument concerning the judging gazes, the disciplining of bodies, the governing of souls, and the dispersion of power into new forms, where men as well as women are encouraged to discipline their bodies through the body ideals connected to consumer culture. According to Foucault, discipline is "essentially corrective" rather than punitive [13]. We have argued that this is made easier because aesthetic body ideals converge with healthy body ideals combined with body affection. Having just enough muscle, according to the ideal, is healthy and makes one beautiful as well. Through the conflation of health and consumerism, or by the commercialization of health, men and women alike are subjected to the mechanisms of advanced capitalism embedded in the discourses of health, fitness and looking good. All the informants reflect these issues, and people with deviant bodies do not seem more affected than others. They have accepted their handicaps as parts of themselves, and beyond that reflect on perfecting their bodies similar to those with normal bodies. The comparative perspective has highlighted that the people with deviant bodies, more than those with normal bodies, 
balance the idea of "being myself" with the idea of "doing the best out of my (bodily) situation.” Most show that it is harder to accept handicaps that are changeable, like being overweight, than harelips, deformed legs and skin injuries. As such, being overweight becomes a double burden.

\section{REFERENCES}

[1] Steen-Johnsen, K. (2004) Individualised communities. Keepfit exercise organisations and the creation of social bonds. Ph.D. Thesis, Universityof Oslo, Oslo.

[2] Wachs, S.L. and Dworkin, F.L. (2009) Body panic. Gender, health and sellingof fitness. New York University Press, New York.

[3] Featherstone, M. (2010) Body, image and affect in consumer culture. Body \& Society, 16, 193-221. doi:10.1177/1357034X09354357

[4] Bugge, A. and Lillebø, K. (2009) Fit, not fat! Change, improvement and imperatives of amendment (fit, ikke fet! Forandring, forbedring Og forvandlings imperativer). In Jacobsen, E. and Asdal, K. Eds., The Responsibility of the Consumer (Forbrukerens Ansvar), Cappelen, Oslo.

[5] Rudd, N.N. and Lennon, S.J. (2000) Body image and appearance-management behaviours in college women. Clothing and Textiles Research Journal, 18, 152-162. doi:10.1177/0887302X0001800304

[6] Edmonds, A. (2010) Learning to love yourself: Esthetics, health, and therapeutics in brazilian plastic surgery. Ethnos, 74, 465-489. doi:10.1080/00141840903201829

[7] Jones, M. (2008) Makeover culture’s dark side: Breasts, death and lolo ferrari. Body \& Society, 14, 89-104. doi:10.1177/1357034X07087532

[8] Foucault, M. (1976) The historyof sexuality. Penguin Books, London.

[9] Rose, N. (1989) Governingthe doul. Free Association Books, London.

[10] Strauss, C. and Quinn, N. (1997) A cognitive theory of cultural meaning. Cambridge University Press, Cambridge.

[11] Crawford, R. (2006) Healthism and the medicalization of everyday life. Health, 10, 401-420. doi:10.1177/1363459306067310

[12] Rose, N. (1999) Powers of freedom: Reframing political thought. University Press, Cambridge. doi:10.1017/CBO9780511488856

[13] Foucault, M. (1979) Discipline and punish: The birth of the prison. Vintage Books, New York.

[14] Champion, H. and Furnham, A. (1999) The effect of media on body satisfaction in adolescent girls. European Eating Disorders Review, 7, 213-228.
doi:10.1002/(SICI)1099-0968(199906)7:3<213::AID-ER V229>3.0.CO;2-W

[15] Bordo, S. (2003) Unbearable weight. University of California Press, London.

[16] McRobbie, A. (2009) The aftermath of feminism. Gender, culture and social change. Sage, London.

[17] Rhode, D.L. (2010) The beauty bias. Oxford University Press, New York.

[18] Atkinson, M. (2008) Exploring male femininity in the "crisis": Men and cosmetic surgery. Body \& Society, 14, 67-87.

[19] Throsby, K. (2008) Happy re-birthday: Weight loss surgery and the new Me. Body \& Society, 14, 117-133.

[20] Wasylkiw, L., Emms, A.A., Meuse, R. and Poirer, K.F. (2009) Are all models created equal? A content analysis of women in advertisements of fitness versus fashion magazines. Body Image, 6, 137-140. doi:10.1016/j.bodyim.2009.01.005

[21] Moore, S.E.H. (2010) Is the healthy body gendered? Toward a feminist critique of the new paradigm of health. Body \& Society, 16, 95-118. doi:10.1177/1357034X10364765

[22] Banner, L.W. (1983) American beauty. The University of Chicago Press, Chicago.

[23] Beuf, A.H. (1990) Beauty is the beast. University of Pennsylvania Press, New York.

[24] Freedman, R.J. (1984) Reflectionson beauty as it relates to health in adolescent females. Women \& Health, 9, 2945. doi:10.1300/J013v09n02_03

[25] Hesse-Biber, S. (1996) Am I thin enough yet? The cult of thinness and the commercialization of identity. Oxford University Press, Oxford.

[26] Labre, M.P. and Walsh-Childers, K. (2003) Friendly advice? Beauty messages in websites of teen magazines. Mass Communication and Society, 6, 379-396. doi:10.1207/S15327825MCS0604_3

[27] Gilbert, K. (1998) The body and young children in popular culture. In: Yelland, N. Ed., Gender in Early Childhood, Routledge, New York.

[28] Moore, L. and MacKinnon, D. (2001) Preadolescent girls and the presentation of self: A dramaturgical perspective. The Alberta Journal of Educational Research, 407, 309324.

[29] Smeesters, D., Mussweiler, T. and Mandel, N. (2009) The effects of thin and heavy media images on overweight and underweight consumers: Social comparison processes and behavioral implications. Journal of Consumer Research, 36, 930-949. doi:10.1086/648688

[30] Ehrenreich, B. (2009) Bright-sided: How the relentless promotionof positive thinking has undermined America. Metropolitan Books, Croydon. 